\title{
LA INTERVENCIÓN COLONIAL DE LA PAZ: TRANSICIONES DESDE UNA LECTURCA DE LARGA DURACIÓN EN COLOMBIA
}

\author{
Julio Roberto Jaime Salas \\ Universidad Surcolombiana, Colombia
}

https://doi.org/10.33676/EMUI_nomads.55.16

\begin{abstract}
Resumen.- La paz es una invención moderno-colonial mutada temporalmente a través de los diferentes sistemas político-económicos emanados de una matriz liberal y materializada en formaciones jurídicas, militares, educativas y sociales. Es decir, se ha configurado en occidente a través de diferentes proyectos que ha respondido a esta misma matriz liberal moderno-colonial con la naturalización de su denominación y el uso indiscriminado de la misma. Cuando se habla de paz, no se habla de un significado universal, su polisemia se materializa en la disputa de diferentes proyectos de senfido, que atraviesan desde las nociones de desarrollo hasta las formas de administración de la vida en el territorio. Entonces, hablar de paz en el presente de Colombia, es hablar de la disputa, negociación y mutación de diferentes proyectos de paz que han configurado el mundo de la vida en Colombia.
\end{abstract}

Palabras clave: Paz, Colonialidad, Desarrollo, Colombia

\section{The colonial intervention of peace: Transitions from a long-term lecture in Colombia}

Abstract.- Peace is a modern-colonial invention temporarily mutated through the different political-economic systems emanating from a liberal matrix and materialized in legal, military, educational and social formations. That is, it has been configured in the West through different projects that have responded to this same modern-colonial liberal matrix with the naturalization of its denomination and the indiscriminate use of it. When we talk about peace, we do not speak of a universal meaning, its polysemy is materialized in the dispute of different projects of meaning, which go from the notions of development to the forms of administration of life in the territory. So, to speak of peace in the present of Colombia, is to talk about the dispute, negotiation and mutation of different peace projects that have shaped the world of life in Colombia.

Keywords: Peace, Coloniality Development, Colombia

El 24 de Noviembre de 2016 a las 11:00 a.m en el Teatro Colón de la ciudad de Bogotá, Colombia, se firmó el Acuerdo Final de Paz entre el grupo insurgente FARC-EP y el Gobierno de Juan Manuel Santos luego de más de 4 años de conversaciones. Este acontecimiento enmarca un periodo estratégico iniciado el 4 de Julio de 1991 con la firma de la Constitución Política de Colombia que instituía luego de un siglo, la paz como un derecho fundamental. 
Este marco estratégico de acontecimientos de 1991 a 2016, ha traído consigo la emergencia de una formación discursiva de/sobre/en torno/para la paz, que ha sido también el correlato de la transición económica y política de Colombia, pero que no puede ser leído, como abstraído de una arquitectura global determinada luego de la Segunda Guerra Mundial con la Conferencia de Bretton Woods y la creación de la Organización de las Naciones Unidas y menos aún, sin la comprensión histórico-político-económico-cultural de las anfictionías moderno-coloniales transmitidas y posteriormente instituidas con el proceso civilizatorio colonizador iniciado en 1492 en los territorios del Abya Yala.

Leer nuestro presente, en la transición hacia la construcción de un imaginario social de porvenir (Castillejo, A. 2015) luego de lo firmado el 24 de Noviembre de 2016, requiere una lectura ontológica crítica del mismo, que nos permita comprender esto que somos, mostrar cómo se ha formado, a que intereses responde, a que racionalidades, a que necesidades, cómo se ha desplazado y modificado. Leer este presente en Colombia, implica develar las condiciones que lo han hecho posible, lo que hoy circula y opera discursivamente como paz, lo que se dice, pero también lo que no, es una entrada, de las múltiples que pueden existir, para hacer esta lectura.

Las diferentes condiciones militares-económico-político-culturalesacadémicas-sociales que han hecho posible la situación de la $\mathrm{paz}^{1}$ son el efecto de una serie transiciones, luchas y deseos a lo largo de la formación republicana, la construcción del estado y la inacabada construcción de un proyecto nacional desde el Siglo XIX hasta nuestro días, y de las cuales aún se sostiene un correlato colonial.(Rojas, 2001; Bolívar, Vázquez, \& González, 2005; F. González, 2015; Guerrero, 2016). Sin embargo, no puede leerse como un proceso lineal o con una tendencia evolutiva. Al contrario, se caracteriza por su discontinuidad, por sus contradicciones, pero también por algunas regularidades.

Esto nos ha permitido establecer tres marcos estratégicos de análisis para develar la situación de la paz, para cartografiarla discursivamente desde tres transiciones económico-políticas que han posibilitado su materialización en lo que leemos hoy como presente, que se superponen, que mutan, se pliegan y se afectan.

Es sobre las transiciones de estos marcos estratégicos, los efectos en lo que somos y las condiciones de posibilidades presentes sobre la que gira este artículo de reflexión.

1 La categoría situación la entenderemos con (Clarke, Friese, \& Washburn, 2015) al referirla como condiciones de posibilidad, interpretación y acción. 


\section{La Post-Independencia, la formación del Estado y las exponsiones para concluir la Guerra en el Siglo XIX}

El siglo XIX en Colombia, luego de la lucha independentista de 1810, se caracterizó por la relación entre civilización (lenguaje), violencia y desarrollo capitalista. (B. González, 1996b, 1996a; Rojas, 2001; Nuñez, 2013). Por un lado, la implementación de los principios del liberalismo económico a través del laissez-Faire fortaleció la integración del país en la segunda mitad del siglo a los mercados mundiales a través de las exportaciones agrícolas. Por ofro lado, 9 guerras civiles generales (1812, 1840, 1851, 1854, 1860, 1876, 1885, 1895,1899-1902), 14 guerras civiles locales, 2 guerras internacionales y 3 golpes de cuartel, caracterizaron la compartimentación sociopolítico cultural regional de Colombia, el regionalismo, y el vacío de poder en los múltiples intentos fallidos de configuración de un Estado-Nación.

Entre estos lados, la sedimentación del deseo civilizador de la elite criolla ilustrada neogranadina como amalgama para la emergencia de nuevas formas cuyo modelo era la civilización europea (Rojas, 2001). Este deseo impulso prácticas económicas, educativas, religiosas y políticas materializadas en las costumbres y hábitos de la cotidianidad, construyendo identidades raciales, de género, clase, religiosas y regionales de un sujeto liberal letrado criollo.

González-Stephan, B. (1996b) describirá "La vida cotidiana en el estado liberal- desde su momento fundacional hasta por lo menos mediados de este siglo- está atravesada por innumerables dispositivos disciplinatorios que convierten a la sociedad civil en un espacio regido por economías de guerra, donde los sujeto que la integran se ven compelidos a conformar un orden por vías de una domesticación pedagógica o médica que opera sutilmente a través de prácticas escrituradas, y, en última instancia, por una represión punitiva. Del mismo modo, también ese orden-obviamente por su naturaleza homocultural- se toma en un campo de negatividades ingobernables, porque el marco epistemológico limitado que les da existencia -la metáfora irreductible de «civilización» y ubarbarie»- las conforma jurídicamente sin alfernativas dentro o fuera de la ley: quiero pensar que las condiciones "salvaje " de cuerpos y lenguas de las no ciudadanías son más bien campos de resistencias, con otras lógicas culturales, con alternativas para repensar otra modernización y no meras negatividades pasivas oscurecidas por el discurso del sujeto liberal letrado, obturadas por la metáfora de la enfermedad, la degeneración y abyección física y moral, la incapacidad verbal, en fin, tachadas de feas, sucias y malas."(p.3)

Civilización, Violencia y desarrollo capitalista, son producto de una misma forma, de una lógica productora de realidad, la realidad histórico-geográfica del colonialismo/colonialidad². Estas formas

2 Al referirnos a Colonialismo/colonialidad tomaremos la distinción hecha por Quijano (2014)"Colonialidad es un concepto diferente, aunque vinculado con el concepto de 
histórico-estructurales y psico-culturales se caracterizaron en la transición del siglo XIX por dominar y explotar sistémica y sistemáticamente las formas de vida, la existencia social: "1) el trabajo y sus productos; 2) en dependencia del anterior, la "naturaleza" y sus recursos de producción; 3) el sexo, sus productos y la reproducción de la especie; 4) la subjetividad y sus productos materiales e intersubjetivos, incluido el conocimiento; 5) la autoridad y sus instrumentos, de coerción en particular, para asegurar la reproducción de ese patrón de relaciones sociales y regular-sus cambios" (Quijano, 2014 p. 290) Territorios, poblaciones y deseos eran parte del objetivo de este enclave Violento Moderno-colonial civilizatorio capitalista.

Durante el Siglo XIX reformas económicas y guerras fueron los relatos visibles historiográficos que han enmarcado el recuerdo y las preguntas sobre este periodo. Sin embargo, es importante resaltar, como lo mencionamos anteriormente, que al hablar de esta transición económico-política en el Siglo XIX, no estamos hablando de sólo una formación económica (Feudalismo-Capitalismo) y una organización política (Colonia-República-Estado-Nación), estamos hablando de un entramado más complejo que hizo posibles múltiples formas discursivas que aún se hacen presentes en silencios, soslayos o plazas públicas como lo es La paz.

El colonialismo económico-político se caracterizó por tener instituciones de tipo extractivo que produjeron un rígido sistema social de castas crearon sistemas productivos basados en la servidumbre y la esclavitud, restringieron el comercio e impusieron pesados tributos; con las luchas independentistas, se estableció una disputa entre el régimen absolutista Borbón Feudal, sus formas institucionales coloniales, y las formas de la democracia liberal que buscaban la creación de mercados libres de trabajo, de tierra y de capital. Las guerras internas impidieron esta transición y eran necesarias exponsiones, en el modo de las anfictionías ${ }^{3}$ griegas que posibilitaran el crecimiento económico y la integración de Colombia al mercado mundial. (Kalmanovitz, 2016)

Es tan sólo en los gobiernos liberales entre 1850 y 1886 a parfir de las políticas económicas de apertura, simplificación tributaria, federalismo

colonialismo. Este último se refiere estrictamente a una estructura de dominación y explotación, donde el control de la autoridad política, de los recursos de producción y del trabajo de una población determinada lo detenta otra de diferente identidad, y cuyas sedes centrales están, además, en otra jurisdicción territorial. Pero no siempre, ni necesariamente, implica relaciones racistas de poder. El colonialismo es, obviamente, más antiguo, en tanto que la colonialidad ha probado ser, en los últimos quinientos años, más profunda y duradera que el colonialismo. Pero sin duda fue engendrada dentro de éste y, más aún, sin él no habría podido ser impuesta en la intersubjetividad del mundo, de modo tan enraizado y prolongado" (p. 286)

3 Las anfictionías en la Grecia Antigua eran Congresos de ligas o confederaciones de pueblos cuyo propósito era reglamentar las relaciones de las tribus de una nación para hacer menos frecuentes las guerras y mediante acuerdos que apelaran a los intereses culturales, políticos y de intercambio económicos de las tribus. (De la Reza, 2009) 
fiscal y fomento de la banca privada (Kalmanovitz, 2016) que se configuró una nueva fuerza económica y social empresarial que tuvo en el libre cambio internacional su apuesta principal, respaldados por el endeudamiento con Gran Bretaña en el marco de lo que se denominaría Pax Británica ${ }^{4}$.

Sin embargo, este auge, de esta clase criolla liberal moderna, se verá truncado por la transición económico-política de 1886 vehiculizada por las guerras de finales del Siglo XIX e inicios del Siglo XX que obligaron a estas clases a configurar un proyecto de paz política que permitiera durante el siglo XX que las políticas monetarias y fiscales fueran prudentes y forjaran el equilibrio macroeconómico de este sector, sus clases, sus instituciones modernas y de la democracia liberal. La paz, la economía, la guerra y la civilización empiezan a entramar un ethos identitario particular en la emergente nación colombiana.

"La élite colombiana que surgió después de la Independencia, era pequeña y relativamente pobre [...] estaba bastante dispersa en una gran extensión del territorio. A pesar de su poco poder económico, esos pocos representantes de la población (seis mil de tres millones de habitantes) fueron los artífices de un régimen de representación que les permitió trazar fronteras definidas entre ellos y el resto de la población: eran letrados en un país en el que el $90 \%$ de la población era analfabeta; eran criollos, descendientes de padres españoles, cuando la mayoría de la población era mestiza, india o negra; la mayoría de ellos eran hombres; los sistemas educativo y legal estaba restringidos sólo para los hombres. En la Colombia de mediados del Siglo XIX, Ia economía política no estaba centrada en la acumulación de la riqueza sino en la acumulación de palabras y capital civilizador. [...] Las batallas constitucionales más importantes y las guerras civiles entre liberales y conservadores se suscitaron alrededor del problema de cómo deberían emplearse las palabras para forjar la misión civilizadora"(Rojas, $2001 \mathrm{pp}$ 140-141)

Las palabras de la guerra y la paz empezaran a circular y hacer parte de la realidad colombiana, negociación, indultos y amnistías serán palabras recurrentes, aunque no lo parezca, desde el Siglo XIX hasta hoy. Las guerras civiles decimonónicas en Colombia produjeron patrones poblaciones, configuraron nuevas demografías territoriales y gramáticas para la conducción regulada ta pacificación y la exacerbación de la atrocidad (Guerrero, 2016).Se inventaron también, lenguajes para el dolor, el sufrimiento, así como olvidos y silencios para las resistencias.

\footnotetext{
4 La Pax Británica es un término que hace referencia al período de dominación mundial británica comprendido entre 1815 y 1914, también llamada época del victorianismo pleno. Se caracterizó por una gran prosperidad económica, sustentada en los principios de la revolución industrial, su objetivo era la paz mundial (Sistema Jurídico universal) y la fraternidad en todo el Imperio.
} 
Al respecto María Teresa Uribe (Uribe, 2003) establece "Lo que sería necesario afirmar es que las iniciativas políticas para evitar, suspender 0 terminar la guerra, fueron tan abundantes y tan plurales como las batallas, las tomas de poblaciones o los encuentros armados en las encrucijadas de los caminos; que a la par con los lenguajes políticos de "los agravios", "la sangre derramada", "la tiranía" y "la conspiración", corrieron parejos los del "perdón y el olvido", "la clemencia" y "la reconciliación" y que si bien Colombia puede pensarse como un país en guerra permanente, también sería preciso recordar que es quizá el país de América Latina con una más larga y más continua experiencia de negociación, transacciones formales e informales, acuerdos políticos, discursos pacifistas e instrumentos jurídicos para la superación de los conflictos armados".(p.30)

Ramirez-Orozco (2012) describirá "De este modo, la gesta de independencia, muy a pesar del cambio absoluto del protagonismo español, mantuvo indemne el orden de dominación, ahora usufructuado por la nueva élite criolla, con las mismas estructuras de concentración de la propiedad del incipiente comercio y de las zonas de explotación agraria. No fue entonces una revolución, en sentido estricto, sino un cambio de élite que conservó intacto, en buena parte el régimen económico y jurídico de los colonialistas. Hubo sin duda un cambio de ricos, pero los pobres siguieron siendo los mismos" p.104

La posindependencia, la organización republicana del Estado Nación derivado de la división de la Gran Colombia luego del Congreso de las anfictionías de 1923, pasando por la Conformación federal de los Estados Unidos de Colombia en 1863 hasta la conformación de la República de Colombia con la Constitución de 1886, trajo consigo varios elementos comunes:

Las guerras estarán caracterizadas por ser de orden étnico-racial, ideológico-político y transitarán entre las formas de la Guerra medieval cristiana de "enemigo justo" a las formas de la guerra moderna sustentado en el ius en bellum y en el ius gentun.

La paz durante este siglo será caracterizada por los procesos diplomático-militares de tradición anfictiónica como las exponsiones que procuraban la protección económica, el sostenimiento comercial y el poder político regional y procesos filosófico-jurídicos que buscaban la regulación de la guerra a través de la mediación, las amnistías, los indultos, las leyes (Constituciones, tratados) para pacificar los territorios. Entre la paz de la Victoria y la paz constitucional (Richmond, 2014a)como formación del proyecto civilizatorio colonial criollo.

Podemos intentar concluir, que Paz, Guerra, Civilización y economía capitalista configuraron un enclave colonial que posibilitó el sostenimiento de una élite que emergió postindependencia, se 
fundamentó en el linaje, utilizó las tecnologías diplomático-militares (Foucault, 2008) para configurar circuitos de poder regional y nacional y diseño culturalmente un modelo civilizatorio moderno liberal a modo de colonialismo interno a través de procesos pacificadores filosóficojurídicos, diplomático-militares, económico-políticos y educativoreligiosos-higiénicos. Sin embargo, pese a ello, también quedaron enterradas, subalternizadas, formas otras, historias miles políticoculturales que resistieron y siguen resistiendo, re-existiendo hasta hoy. Guerra y Paz, civilización y violencia, Economía y política, no son posiciones distantes, disímiles, son caras de una misma moneda.

A partir de los trabajos de Uribe (Uribe, 2003, 2006; Uribe \& López, 2008; Uribe, 2011)y Guerrero (2016) podemos relacionar en la Tabla 1 las principales exponsiones realizadas durante el Siglo XIX en los diferentes tránsitos de la Guerra y el proyecto civilizatorio moderno-colonial.

\section{Tabla 1. Transiciones Económicas políticas, formas de colonialidad/modernidad y Paz en el Siglo XIX}

\begin{tabular}{|c|c|c|c|}
\hline \multicolumn{2}{|c|}{ Transiciones Político-económicas } & \multirow{2}{*}{$\begin{array}{l}\text { Formas de } \\
\text { Colonialida } \\
\text { d/modernid } \\
\text { ad }\end{array}$} & \multirow{2}{*}{$\begin{array}{l}\text { Exponsiones, } \\
\text { Anfictionías y acuerdos } \\
\text { para la construcción } \\
\text { de paz o finalización } \\
\text { de la Guerra }\end{array}$} \\
\hline & Colombia & & \\
\hline $\begin{array}{ll}\text { Congreso de las } \\
\text { Anfictionías }\end{array}$ & $\begin{array}{l}\text { Modelo } \\
\text { Monárquico- Feudal }\end{array}$ & $\begin{array}{l}\text { Colonialism } \\
\text { o Clásico }\end{array}$ & \\
\hline $\begin{array}{l}1823 \\
\text { (Gran Colombia) }\end{array}$ & $\begin{array}{lr}\text { SXVI-XIX- } & \text { en } \\
\text { transición con el }\end{array}$ & $\begin{array}{l}\text { Colonialism } \\
\text { o Interno }\end{array}$ & \\
\hline $\begin{array}{l}\text { Constitución de } \\
1832 \text { bajo el } \\
\text { régimen }\end{array}$ & capitalismo primitivo & Colonialida & $\begin{array}{l}\text { Pasto } 3 \text { de Júlio de } \\
1839\end{array}$ \\
\hline $\begin{array}{l}\text { presidencialista de } \\
\text { Santander }\end{array}$ & $\begin{array}{l}\text { Instituciones } \\
\text { Coloniales }\end{array}$ & $\begin{array}{l}\text { (Quijano, } \\
\text { 2014) }\end{array}$ & $\begin{array}{l}\text { Los árboles } 22 \text { de } \\
\text { febrero de } 1840\end{array}$ \\
\hline $\begin{array}{l}\text { (Estado de la } \\
\text { Nueva Granada) }\end{array}$ & & & $\begin{array}{l}\text { Itagüí } 3 \text { de febrero de } \\
1841\end{array}$ \\
\hline $\begin{array}{l}\text { Constitución } \\
1843\end{array}$ & Introducción a las & $\begin{array}{l}\text { d del Ser } \\
\text { (Maldonad }\end{array}$ & $\begin{array}{l}\text { Túquerres y Sitio Nuevo } \\
\text { en } 1841\end{array}$ \\
\hline Constitución Liberal & $\begin{array}{l}\text { librecambistas del } \\
\text { Liberalismo }\end{array}$ & $\begin{array}{l}\text { O-Torres, } \\
\text { 2007) }\end{array}$ & $\begin{array}{l}\text { Panamá } 31 \text { de } \\
\text { diciembre de } 1841\end{array}$ \\
\hline $\begin{array}{l}\text { Constitución } \\
1858\end{array}$ & $\begin{array}{ll}\text { económico. } & \\
\text { Transición } & \text { del } \\
\text { Capitalismo } & \\
\text { Primitivo a la } \\
\text { modernización }\end{array}$ & & $\begin{array}{l}9 \text { Decretos de Indultos } \\
\text { entre } 1851 \text { y } 1853 \\
\text { (Junio, Agosto, } 2 \text { en } \\
\text { Octubre y } 2 \text { en } \\
\text { Noviembre de } 1851 \text {, }\end{array}$ \\
\hline
\end{tabular}




\begin{tabular}{|c|c|c|}
\hline $\begin{array}{l}\text { Constitución de } \\
\text { Rionegro de } 1863 \\
\text { (Estados Unidos de } \\
\text { Colombia) } \\
\text { Constitución del } \\
\text { Proyecto de la } \\
\text { Regeneración de } \\
1886 \\
\text { (República de }\end{array}$ & industrial & 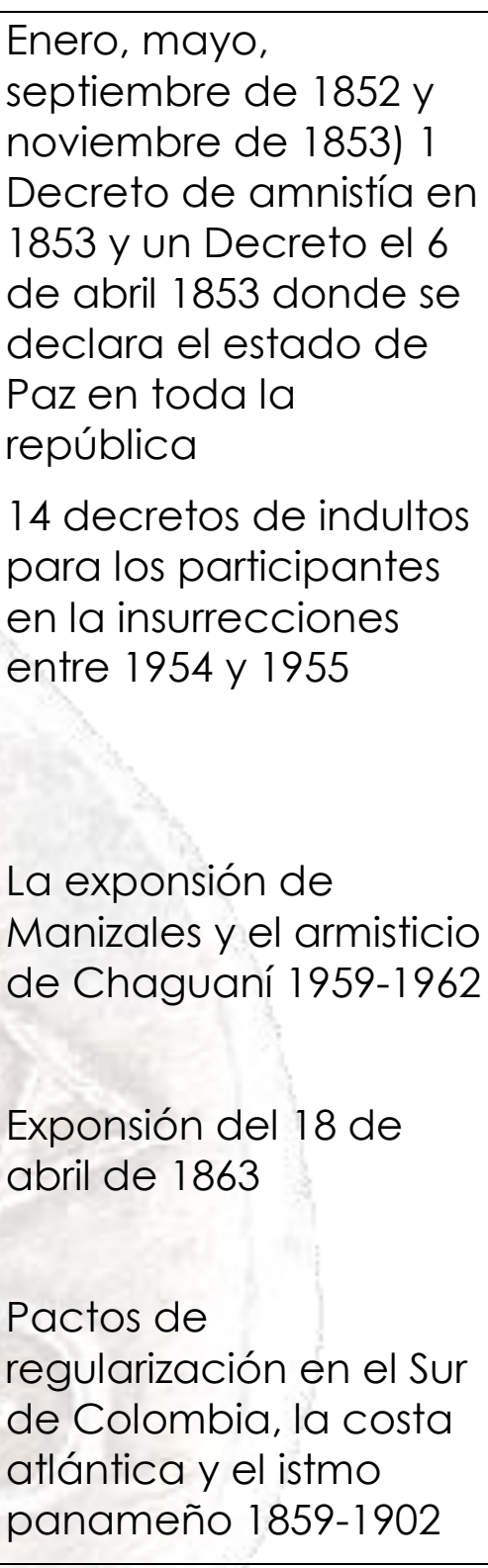 \\
\hline
\end{tabular}

Fuente: Elaboración propia

El proyecto político-económico racial católico de la Constitución de 1886 y la mutación de las formas de violencia y pacificación del Siglo $\mathrm{XX}$

El Siglo XX en Colombia, inicia pacificado, política, económica, militar y religiosamente. El Proyecto proteccionista de la regeneración, liderado por el Presidente Núñez, con un fuerte componente étnico- racial enfocará su acción gubernamental en dos objetivos: la protección económica de la élite nacional criolla y la protección de la tradición hispánico-católica, es decir un hibrido entre el mito moderno y las nostalgias monárquico-medievales, entre la búsqueda del crecimiento económico a través del proyecto civilizatorio moderno del liberalismo 
político-económico y las formaciones psico-socio-culturales coloniales que funcionaron como el espejo del imaginario de la nueva élite emergente colombiana, del nuevo Sujeto moderno, liberal, criollo (Mestizo), letrado consagrado al Corazón de Jesús(Castro-Gómez, 2008; Melgarejo, 2008).

Así mismo, este inicio de siglo estuvo antecedido por guerras civiles, la pobreza que trajo consigo la continuidad de las estructuras de dominación colonial y la diferenciación de las identidades básicas de los dos partidos tradicionales: Liberal y Conservador, los cuales, más que como fuerza política se configuraron como subculturas de la vida cotidiana (Pécaut, 2001; Sánchez \& Meerteens, 2006).

En las tres primeras décadas de siglo XX se habían creado las bases para el proceso del desarrollo industrial del país y su vinculación con el mercado mundial, el comienzo del endeudamiento externo y la nula inversión en materia social (Ramírez-Orozco, 2012)la expansión de la producción agraria a partir de la consolidación de la exportación cafetera y la concesión de extensiones de tierras baldías para el latifundio ganadero, la llegada del ferrocarril y las máquinas de vapor que van a navegar por los ríos de las tumbas, Magdalena y Cauca, dejando a su paso el humo que se mezcla con el aire espeso que va brotando de la tierra. (Jaime-Salas, 2012)

La concentración legal y violenta de la tierra, la consolidación en el país del café como renglón principal de la economía nacional y de las exportaciones, la industrialización a partir de hidrocarburos, una incipiente industria productora de químicos (como el ácido sulfúrico), empresas cementeras, la industria textil, cervecera y de chocolates obligaron a la modernización del país (Ramírez-Orozco, 2012).

Estas transformaciones van a generar la emergencia de movimientos de clase que van a desbordar el bipartidismo imperante dejado por el Siglo XIX, como son la expresión del movimiento obrero, del cual de unas de sus diversas tendencias surgirá el Partido Comunista Colombiano en 1930. De igual manera emerge el movimiento campesino, antecedido por las luchas que desde 1850 se venían dando en las zonas periféricas o de frontera por los terrenos baldíos, que se denominó proceso de colonización campesina y que su rápida organización y politización a mediados de los treinta va a recrudecer el conflicto entre hacendados ("dueños legales, pero no legítimos") y campesinos por la tenencia de la tierra en zonas geopolíticamente estratégicas.

Antesala que les dará la bienvenida a los gobiernos liberales de Olaya Herrera y López Pumarejo, luego de cincuenta años de hegemonía conservadora. Quienes iniciaron el proceso de modernización del Estado, y el último, tras la bandera de la "Revolución en marcha" dará repuestas a los conflictos agrarios con la Ley de Tierras o Ley 200, la cual será una "solución terrateniente al problema agrario, mediante la conversión del latifundista en empresario capitalista y la consolidación 
de la burguesía industrial como socio de la dominación, sin antagonizar a la oligarquía tradicional"(Sánchez \& Meerteens, 2006 p.60).

Cada uno de estos acontecimientos y los procesos particulares que cada región en disputa y agitación venía viviendo van a desencadenar en 1947 un balance de 14.000 víctimas en los departamentos de Boyacá y los Santanderes, los cuales serán el vaticinio de lo que sucedería en Colombia después del 9 de abril de 1948 con el asesinato de Gaitán. Situación que tuvo su más alta expresión en las regiones periféricas con la creación de las Juntas Revolucionarias, gobiernos populares y milicias campesinas.

Estos antecedentes van a abrir paso a la coyuntura crítica narrada como La Violencia y que se dio en cuatro fases entre 1946 -1966 (Oquist, 1978; Sánchez, 1991; Pécaut, 2001; Bolívar et al., 2005) y que dejaran el siguiente balance en la primera mitad del siglo XX:

- Pacto político-económico pacificador: se establece una alianza entre partidos políticos, gremios económicos y la institución militar para "apaciguar", una forma dulce de llamar la pacificación, a la población. En un primer momento con el ascenso al poder del militar Rojas Pinilla, seguida de la Junta militar de Gobierno y concretada luego de los Pactos Benidorm en 1956, marzo y Sitges en 1957 con el denominado Frente Naciona

- $\quad$ Ausencia de reformas democráticas: La Constitución de 1886 se consolida como régimen político moderno estatal y pese a pocos intentos de reformas en 1930, con Rojas Pinilla y en la Junta Militar (19571958) prevalece y su inflexión profunda se dará a partir del pacto de las élites presionado por los empresarios, denominado Frente Nacional.

- Exclusión política: Se consolidó una hegemonía bipartidista denominada Frente Nacional que excluyó cualquier forma alternativa de participación política, en la forma de una Paz Política que estuvo acompañada de fraudes, el clientelismo cómo práctica y la militarización

- Problema agrario no resuelto: Pese a las promesas de reforma iniciadas con el Partido Liberal entre 1920 y 1935, estas no se materializan, y la lógica de usos, apropiación y tenencia de la tierra se amalgaman en la forma híbrida de un modelo señorial-feudal industrializado, adaptado al mercado internacional y sostenido por la práctica del despojo.

- $\quad$ Tradición de violencia en la resolución de conflictos: La gramática de la violencia heredada del Siglo XIX se legítima como expresión institucionalizada de relación, desde los espacios cotidianos urbanorurales, estatales, para-estatales e insurgentes.

- $\quad$ Actores que optan por la vía armada: Esta Gramática de (des) orden establecido (pacificado), sostenido por múltiples manifestaciones de violencias (Directas, estructurales, simbólico-culturales) hacen posible 
la emergencia de actores y agrupaciones que optan por la vía armada como solución político-militar a conflictos profundos.

- Negociación, amnistías e indultos acomodados y truncados: La Violencia trae consigo la configuración de pactos, negociaciones y acuerdos para la dejación de armas, la desmovilización y la reintegración de las guerrillas campesinas liberales y los actores estatales y paraestatales; sin embargo, en el caso de las guerrillas, estos fueron incumplidos por parte del estado y terminaron con el asesinato de la mayoría de sus líderes.

- Violencia económica: Aunque más sutil, fue determinante en este periodo, se incrementó la intervención estatal con la Ley 1 de 1959, las políticas proteccionistas arancelarias, focos de industrialización en las periferias, la llegada de la Cepal con el "Plan Cuatrienal de Inversiones" y el diseño y ejecución de un plan desarrollo articulado con la "Alianza para el progreso" en 1961 como forma de adaptación a los modelos internacionales, efecto de la participación en el mercado mundial y control insurreccional luego de la Revolución Cubana iniciada el 1 de enero de 1959. (Ramírez-Orozco, 2012)

Intervención Internacional: Se establece en tres vías, económica, política y militar. Económica, materializada en la presencia del recién creado Banco Interamericano de desarrollo y la implementación de la política de los EE. UU. Alianza para el progreso. Política, en la injerencia directa e indirecta con las élites nacionales para el desarrollo de cada gobierno. Finalmente, militar, en el asesoramiento, adiestramiento y operación militar en terreno a través de políticas de contrainsurgencia que en la segunda mitad del siglo XX se agudizarán configurando la subordinación estratégica en Colombia. (Vega-Cantor, 2015)

La segunda mitad del siglo XX inicia con una guerra insurgente planteada por las guerrillas (FARC, EPL y ELN), de carácter ideológico y de naturaleza política inscrito en la lógica de la Guerra Fría por un lado y por otro, la configuración del marco legal del paramilitarismo (19651984) (MOVICE, 2013; Moncayo, 2015; Giraldo, 2015; Estrada, 2015)

Este periodo se desarrolla entre el Frente Nacional (Lleras Camargo 1958-1962, León Valencia 1962-1966, Lleras Restrepo 1966-1970, Pastrana Borrero 1970-1974) y la implementación del Estatuto de Seguridad con Julio César Turbay Ayala 1978-1982.

Caracterizado por la adopción de la estrategia paramilitar a través del Decreto 3398 de 1965 y la Ley 48 de 1968, es un periodo que se presenta entre una tensa calma (Paz política) la militarización gradual de diferentes espacios de la vida cotidiana, el fortalecimiento de las Fuerzas Militares con intervención de EEUU, la fuerte presencia de movimientos sociales, obreros, estudiantiles y campesinos y la aparición de grupos insurgentes que respondían a la continuidad de los conflictos estructurales colombianos (M-19, Movimiento Armado Quintin Lame, 
Partido Revolucionario de los Trabajadores PRT y el Comando Ricardo Franco).

En el marco de la Guerra Fría, la crisis del modelo del Estado de Bienestar por parte de EE. UU. se establecen una serie de reformas a las políticas económicas que propendía por la liberalización de los mercados y su respectiva globalización, en las que se inserta Colombia, sin tener la suficiente infraestructura y liderado por el sector empresarial Antioqueño. Sin embargo, el modelo económico colombiano en general en este periodo mantuvo el proteccionismo, la represión financiera y la mesura ante el mercado internacional de capitales.

Así mismo, el orden político global económico en la región latinoamericana significó una apertura a partir de 1970 a un proceso expropiatorio, neoextractivista, dirigido a la captación de la Inversión Extranjera Directa IED, que posibilitó el ingreso de grandes corporaciones transnacionales en los territorios de manera gradual y progresiva. Se establece un nuevo ciclo colonial, que se sedimenta en el terrorismo de Estado (Expansión paramilitar y pacificación de las poblaciones y los territorios) en el continente, argumentado por la eliminación de la "amenaza comunista" entre los sesenta y setenta y que se prolonga a la violencia disciplinadora de la deuda externa y los ajustes estructurales de los ochenta y se completa, en los noventa, con las denominadas políticas del Consenso de Washington (apertura y liberalización comercial y financiera, desregulación y flexibilización, privatizaciones generalizadas) (Machado-Aráoz, 2010, 2012, 2013)

Este nuevo ciclo colonial no será ajeno a Colombia, aunque de manera soterrada, se adhiere sutilmente en las reformas económicas, políticas y militares, se verá restringido por la fuerte agitación social y la proliferación de grupos guerrilleros enclavados en espacios geopolíticos y culturales de frontera en donde el estado no había podido tener presencia institucional, ni control territorial.

De esta manera, el conflicto armado colombiano pasa de guerra bipolar (Estado-guerrillas) a ser multipolar por el fenómeno paramilitar interferida por el fenómeno del narcotráfico. Adquiere importancia la lucha por el control territorial y entra en una dinámica de degradación con un evidente incremento de la intervención norteamericana.

Frente a esta dramática situación de descomposición social derivadas de las irresueltas causas de la violencia estructural, las cuales, a su vez, son la continuación de las formas moderno-coloniales hibridadas y ajustadas por la elite criolla en la transición económico-política nombrada "Independencia", el Gobierno Conservador Betancurt en 1982 responderá a través de una política de paz.

La paz, luego de dos siglos de una gramática de guerra y violencia posicionada en el discurso cotidiano e institucional, aparece como 
política de Gobierno. El 28 de marzo de 1984 en La Uribe, Meta, se firmó inicialmente una tregua bilateral con las FARC-EP, del cual surgió el partido político Unión Patriótica (UP), declaró el cese de los enfrentamientos, orientado hacia la finalización del conflicto armado entre esta guerrilla y el Estado, además su reincorporación política y social.(Villarraga, 2015)

Sin embargo, la política de Paz de este gobierno fracasa, no logra el respaldo nacional, ni garantizar lo pactado con los sectores armados. Desconfianza, frustración y fortalecimiento político-militar deja este periodo gubernamental. Con este panorama el Gobierno Liberal de Virgilio Barco, gana las elecciones de 1986 y con la declaración de "mano tendida, pulso firme" asume el desafío de la institucionalización de la paz, a partir de reformas económicas parciales dirigidas a la liberalización de los mercados, la paulatina desaparición del Estado en la regulación del comercio internacional, así como la disminución arancelaria, con "el propósito de superar la pobreza y la exclusión social para acabar con las razones objetivas de la violencia y [promover] una estrategia sustentada en presupuestos de reconciliación, rehabilitación y normalización" (Villarraga, 2015 p.45)

En este sentido, logra establecer una agenda de paz con el M-19 dirigida a la conformación de una Asamblea Constituyente en el Acuerdo del Tolima en enero de 1989, proceso al que se sumarían entre mayo y junio de 1990 el EPL, PRT y el Quintín Lame, finalizando con un Acuerdo Político en marzo de 1990 con el M-19 para el desarme, desmovilización y reintegración política.

Iniciativas de paz, indultos y amnistías contrastarían en este segundo periodo con el accionar paramilitar y el narcoterrorismo de los carteles de Cali y Medellín por el control económico, político y territorial. Entre 1985 y 1989 el paramilitarismo se enfocó en el exterminio de la Unión Patriótica, el movimiento político A Luchar, líderes sociales y sindicales en diferentes territorios regionales urbanos y rurales del país.

Esta segunda mitad del siglo veinte se caracterizará también por la ausencia de reformas económicas y políticas sustanciales que consolidaran la forma silenciosa que sostiene este complejo entramado social, la violencia estructural. Desde el Frente Nacional a los Gobiernos de la década del 80 , cada gobierno diseño planes cuatrienales sin tener en cuenta los anteriores, con el intento de dar respuesta a las transformaciones de la política económica global que comienzan con el acuerdo de Bretton Woods en 1944, siguen con el disciplinamiento internacional con la deuda externa y que se orientarían a la liberalización comercial y financiera, la desregulación y flexibilización y las privatizaciones generalizadas en los sectores de educación y salud a partir de 1990.

En la siguiente Tabla, se sintetizarán las transiciones económico-políticas, las formas de colonialidad/modernidad y Paz que se harían evidentes 
durante el siglo XX y que se canalizarán el 4 de Julio de 1991 con la Constitución Política de Colombia

\section{Tabla 2. Transiciones Político-económicas, formas de colonialidad/modernidad y Paz en el Siglo XX}

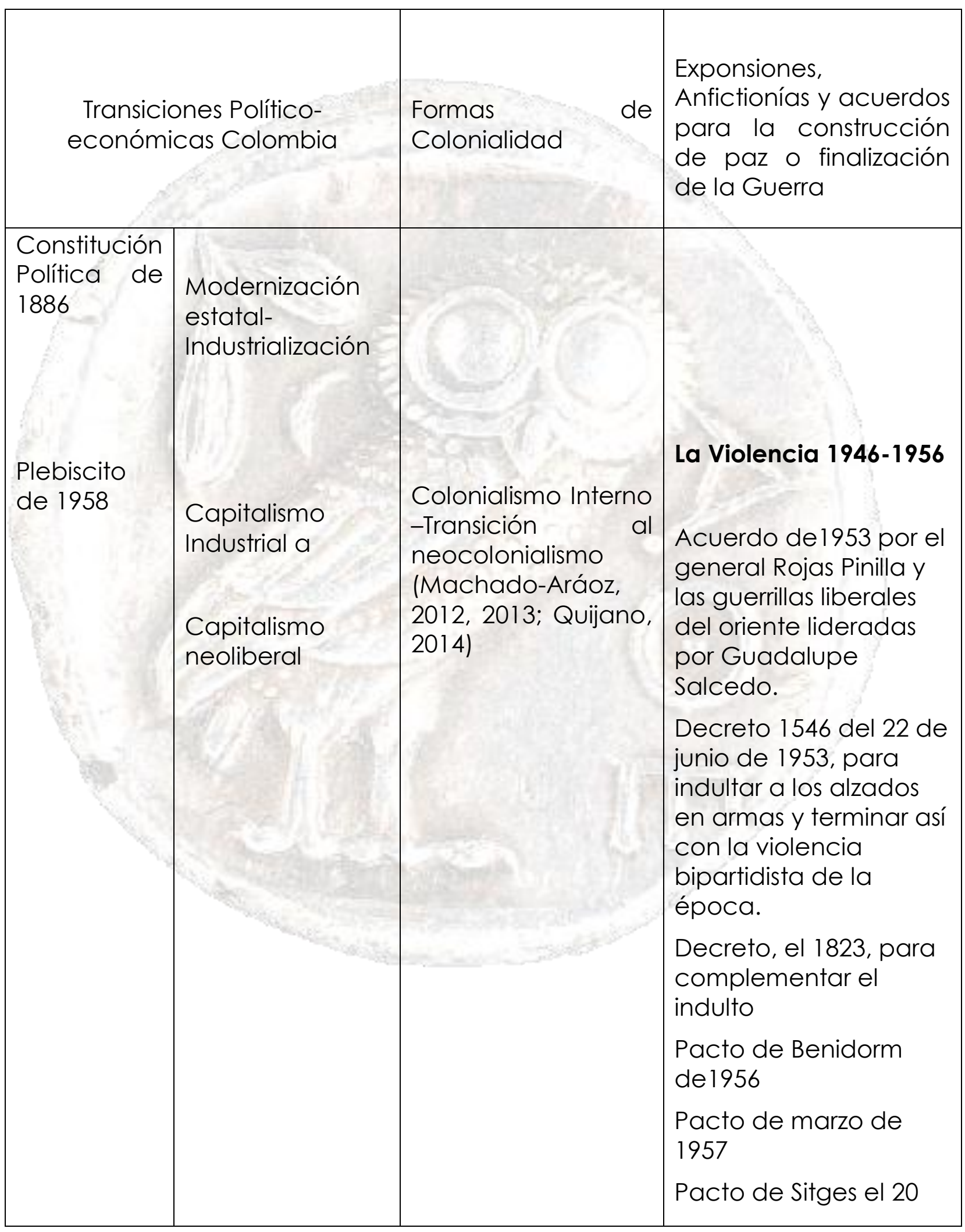




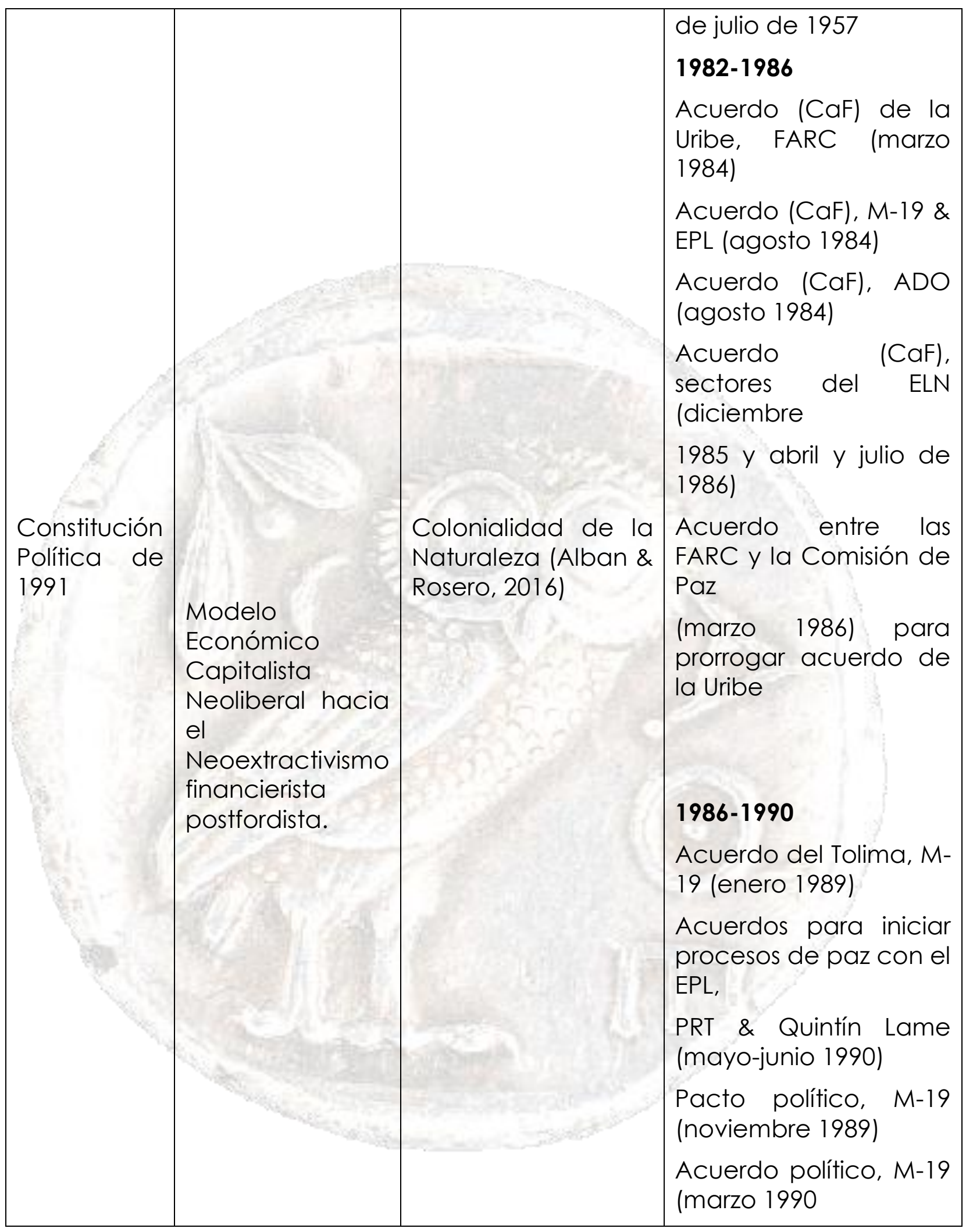




\section{La guerra y la paz en la Constitución de 1991: La matriz Liberal generativa de los proyectos de Paz contemporáneos}

En Colombia, durante las siguientes tres décadas (1991-2018) los discursos sobre la paz ganaron una mayor apropiación y visibilidad por parte de diferentes sectores de la sociedad y un nivel de institucionalización por parte de las organizaciones del Estado, sin ser una política de estado. Es así que Colombia tiene uno de los conflictos más largos del mundo, caracterizado por su degradación y complejidad, pero también uno de los más largos esfuerzos sostenidos para buscar una salida negociada al mismo (García-Durán, 1992, 1995, 2001, 2006a, 2006b, 2009a, 2009b), para buscar la paz. Sin embargo la gramática de la guerra es la misma y las paces son artificiales.

Entre la solución armada planteada por los gobiernos de Turbay Ayala (1978 - 1982) y Uribe Vélez (2002- 2010) y la solución negociada iniciada por Betancourt (1982- 1986), Barco (1986-1990) y continuada por Gaviria (1990-1994), Samper (1994-1998), Pastrana (1998-2002) y finalmente por el actual Gobierno de Santos (2010-2014)(2014-2018) se han construido, debatido, performado y disputados los proyectos sobre la paz hasta convertirse en discurso obligatorio de la política gubernamental municipal, departamental y nacional e incluso de la política cotidiana de las familias, los barrios y las diferentes comunidades y formas de organización o movilización social.

Al mismo tiempo, por disposición constitucional, sólo el presidente de la República, puede dirigir los procesos de negociación con los actores levantados en armas contra el Estado "De este modo, todos los procesos de paz son cuatrienales, dependen del ciclo electoral y de la suerte de los presidentes en la arena política [...] así, pues, cada mandato presidencial se puede ver como una cadena de rupturas, sobresaltos, improvisaciones alrededor de una mesa de elitistas." (Palacios, 2012 pp- 138-142). De esta manera, los proyectos de paz se han hecho posibles de acuerdo con las condiciones cuatrienales de cada gobierno, que independiente de la estrategia de pacificación o discurso empleado, los actores del momento han respondido a la coyuntura sociopolítica, las presiones de la arquitectura internacional liderada por las Naciones Unidas o grupos corporativos internacionales o las tendencias de opinión construidas por los medios de comunicación.(Palacios, 2012; F. González, 2015; Villarraga, 2015).

Estos esfuerzos permanentes por la construcción de Paz, devienen de 4 condiciones: 1) la falta de continuidad institucional de la paz por parte de los distintos Gobiernos (paz cuatrienal) 2) la competencia entre los grupos insurgentes dentro de las diferentes negociaciones, lo cual se ha traducido en la profunda fragmentación de la izquierda radical. (Pizarro, 2017 ) 3) La permanencia de la violencia estructural y cultural operada a través de las diferentes formas de colonialidad y colonialismo en los territorios y poblaciones 4) El sostenimiento de un proyecto político- 
económico de Estado democrático-liberal- capitalista mayormente centralizado que opera intermitente en las regiones con el soporte de grupos de poder mafiosos, militares, paramilitares y/o religiosos locales.

La intermitencia institucional, los procesos de negociación truncados y la construcción de múltiples paces artificiales en el marco de una misma guerra se pueden ver materializados en la configuración de los diferentes planes de desarrollo establecidos entre 1991 y 2018:

\section{Tabla 3. Configuración de los planes de desarrollo}

\begin{tabular}{|c|c|c|c|}
\hline $\begin{array}{ll}\text { Plan } & \text { de } \\
\text { Desarrollo }\end{array}$ & Objetivo & Presidente/periodo & $\begin{array}{l}\text { Exponsiones, } \\
\text { Anfictionías y } \\
\text { acuerdos para la } \\
\text { construcción de } \\
\text { paz o finalización } \\
\text { de la Guerra }\end{array}$ \\
\hline $\begin{array}{l}\text { La revolución } \\
\text { pacífica }\end{array}$ & $\begin{array}{l}\text { Disminuir la } \\
\text { intervención del } \\
\text { Estado } \\
\text { haciendo que } \\
\text { se concentre en } \\
\text { sus funciones } \\
\text { básicas. } \\
\text { Elevar el ingreso } \\
\text { y el nivel de vida } \\
\text { de los grupos } \\
\text { necesitados. } \\
\text { Obtener una } \\
\text { tasa de de } \\
\text { crecimiento del } \\
\text { cinco por ciento } \\
\text { anual promedio } \\
\text { y doblar la } \\
\text { duplicación del } \\
\text { ingreso per } \\
\text { cápita en treinta } \\
\text { años }\end{array}$ & $\begin{array}{l}\text { Cesar } \quad \text { Gaviria } \\
\text { Trujillo 1990-1994 }\end{array}$ & $\begin{array}{l}\text { Acuerdo final, } \\
\text { PRT (Enero 1991); } \\
\text { EPL (febrero } \\
\text { 1991); Quintín } \\
\text { Lame (mayo } \\
\text { 1991) } \\
\text { Acuerdo final, } \\
\text { Comandos } \\
\text { Ernesto Rojas } \\
\text { (marzo 1992) } \\
\text { Acuerdo final, } \\
\text { CRS (Abril 1994) y } \\
\text { Frente Garnica } \\
\text { (junio 1994) } \\
\text { Acuerdo de } \\
\text { Coexistencia, } \\
\text { Milicias de } \\
\text { Medellín } \\
\text { (mayo 1994) }\end{array}$ \\
\hline El salto social & $\begin{array}{l}\text { Orientar la } \\
\text { acción del } \\
\text { Estado y de la } \\
\text { sociedad civil } \\
\text { hacia } \\
\text { crecimiento } \\
\text { integral de }\end{array}$ & $\begin{array}{l}\text { Ernesto Samper } \\
\text { Pizano 1994-1998 }\end{array}$ & $\begin{array}{ll}\text { Acuerdo } & \text { final, } \\
\text { MIR-COAR } & \text { (julio } \\
\text { 1998) } & \end{array}$ \\
\hline
\end{tabular}




\begin{tabular}{|c|c|c|c|}
\hline & \begin{tabular}{|lll} 
la persona \\
humana y el \\
desarrollo \\
solidario de la \\
comunidad \\
colombiana.
\end{tabular} & & \\
\hline $\begin{array}{l}\text { Cambio para } \\
\text { construir la } \\
\text { paz }\end{array}$ & $\begin{array}{|lr|}\text { Buscar } & \text { y } \\
\text { conservar la } \\
\text { paz, con el fin } \\
\text { de ubicar al país } \\
\text { en } \\
\text { una senda de } \\
\text { crecimiento } \\
\text { sostenible con } \\
\text { cohesión social. }\end{array}$ & $\begin{array}{l}\text { Andrés Pastrana } \\
1998-2002\end{array}$ & 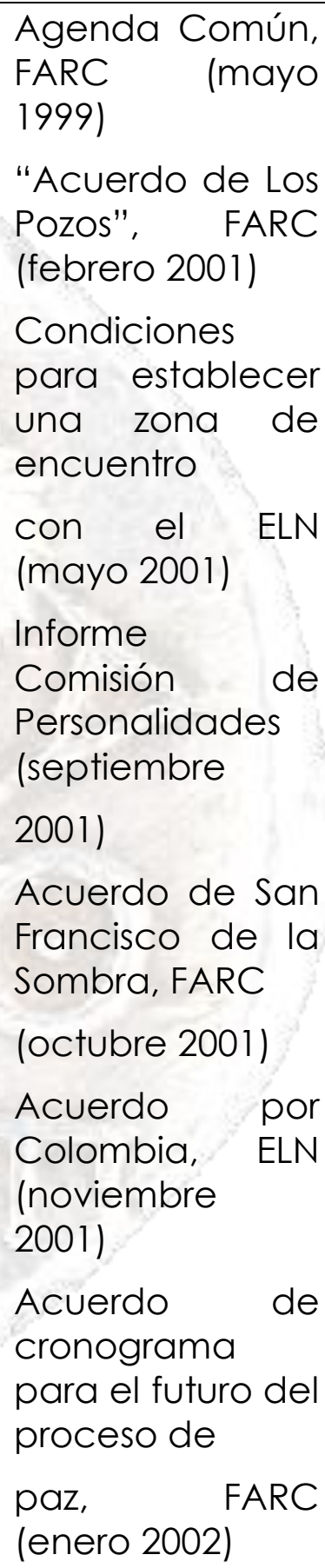 \\
\hline $\begin{array}{l}\text { Hacia un } \\
\text { Estado } \\
\text { Comunitario }\end{array}$ & \begin{tabular}{|l|} 
Brindar \\
seguridad \\
democrática, \\
que asegure la \\
viabilidad de la \\
\end{tabular} & $\begin{array}{l}\text { Álvaro Uribe Vélez } \\
2002-2006\end{array}$ & $\begin{array}{l}\text { Acuerdo de } \\
\text { Santa Fé de } \\
\text { Ralito, AUC (julio } \\
\text { 2003) }\end{array}$ \\
\hline
\end{tabular}




\begin{tabular}{|c|c|c|c|}
\hline & $\begin{array}{|lr|}\text { democracia } & \text { y } \\
\text { afiance la } & \\
\text { legitimidad del } \\
\text { Estado, Impulsar } \\
\text { el crecimiento } \\
\text { económico r } \\
\text { sostenible, } \\
\text { Construir } & \\
\text { equidad social, } \\
\text { mejorando r la } \\
\text { distribución del } \\
\text { ingreso y } & \text { el } \\
\text { crecimiento } & \\
\text { económico, } & \\
\text { Incrementar la } \\
\text { transparencia y } \\
\text { eficiencia r del } \\
\text { Estado, r }\end{array}$ & & $\begin{array}{l}\text { Acuerdo para } \\
\text { involucrarse en } \\
\text { las } \\
\text { negociaciones } \\
\text { con los } \\
\text { paramilitares del } \\
\text { Bloque Central } \\
\text { Bolívary } \\
\text { Vencedores de } \\
\text { Arauca } \\
\text { (noviembre } \\
2003 \text { ) }\end{array}$ \\
\hline $\begin{array}{l}\text { Estado } \\
\text { Comunitario: } \\
\text { desarrollo } \\
\text { para todos }\end{array}$ & 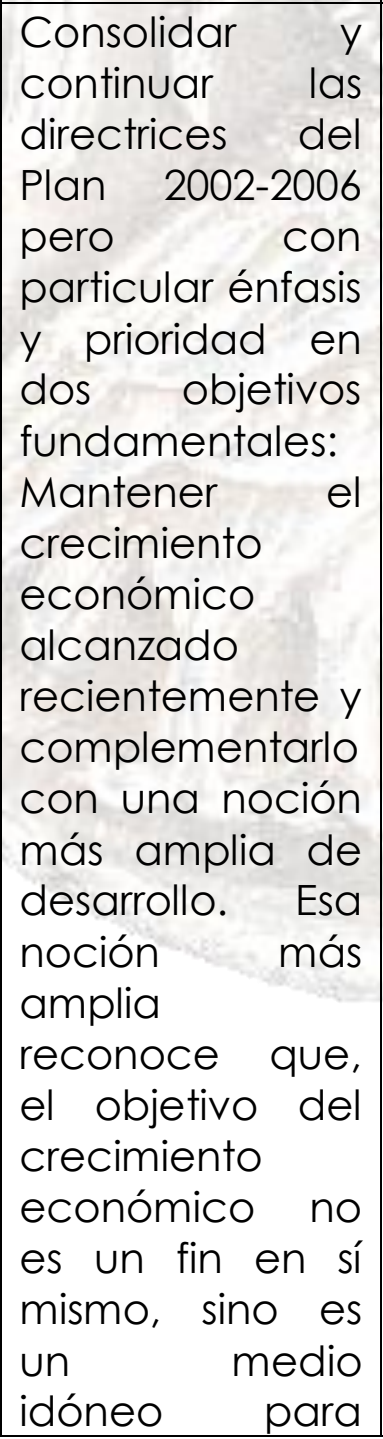 & $\begin{array}{l}\text { Álvaro Uribe Vélez } \\
2006-2010\end{array}$ & \\
\hline
\end{tabular}




\begin{tabular}{|c|c|c|c|}
\hline & $\begin{array}{|ll|}\text { alcanzar } & \text { una } \\
\text { sociedad } & \text { más } \\
\text { justa } & \\
\end{array}$ & & \\
\hline $\begin{array}{l}\text { Prosperidad } \\
\text { para Todos }\end{array}$ & 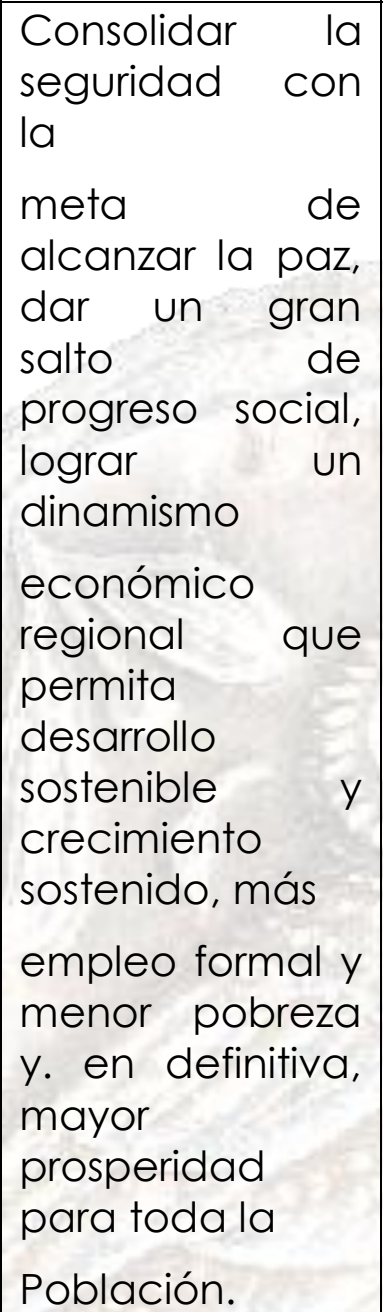 & $\begin{array}{ll}\text { Juan } & \text { Manuel } \\
\text { Santos } & \\
2010-2014 & \end{array}$ & \\
\hline $\begin{array}{l}\text { Todos por un } \\
\text { nuevo país }\end{array}$ & 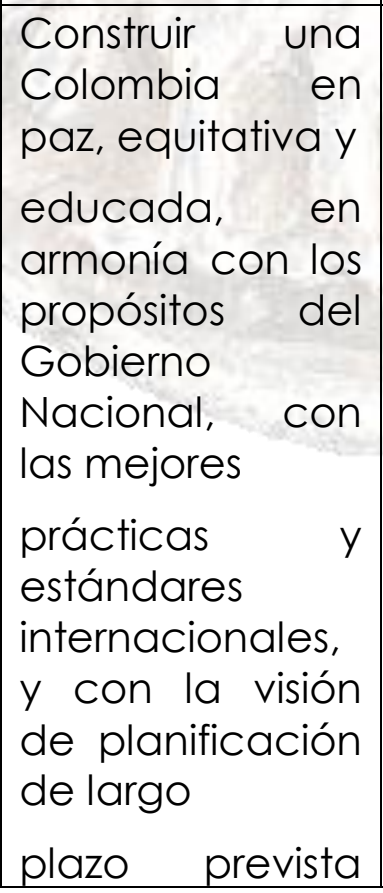 & $\begin{array}{ll}\text { Juan } & \text { Manuel } \\
\text { Santos } & \\
2014-2018 & \end{array}$ & $\begin{array}{l}\text { Acuerdo Final al } \\
\text { Conflicto entre } \\
\text { FARC EP-Estado } \\
\text { Colombiano } \\
2016 \\
\text { Ciclo de } \\
\text { Conversaciones } \\
\text { ELN -Gobierno } \\
\text { Nacional }\end{array}$ \\
\hline
\end{tabular}




\begin{tabular}{|l|l|l|l|}
\hline & $\begin{array}{l}\text { por los objetivos } \\
\text { de desarrollo } \\
\text { sostenible }\end{array}$ & \\
\hline
\end{tabular}

\section{Fuente: Elaboración Propia}

La paz ha sido el correlato de los proyectos de desarrollo gubernamental establecidos en los últimos 30 años que responden a la agudización de los procesos de liberalización de la vida y los territorios y a las recetas/manuales de la intervención internacional humanitarista neoliberal (Democracia liberal y capitalismo afectivo y neoextractivo). Situación similar a otros procesos de negociación y transición del mundo en donde se configura un simulacro de la paz (paz artificial/imperfecta) mientras permanecen latentes o manifiestas las condiciones estructurales de su prolongación, como lo son los casos de Cambodia, Bosnia Herzegovina, Kosovo, Timor del Este y Mozambique. (Richmond, 2011)

Luego del primer año de implementación de los Acuerdos establecidos entre el Estado colombiano y la guerrilla de las FARC-EP, tan sólo un 18\% de lo pactado se ha cumplido (Instituto KROC, 2017), correspondiente a situaciones de tipo superficial y no estructural, aunque la dejación de armas de las FARC se ha cumplido a cabalidad, el cumplimiento estatal es precario y circunstancial, con el telón de fondo del incremento de conflictos socioambientales que ha traído consigo el asesinato selectivo de líderes sociales y la emergencia de nuevos grupos armados que se disputan el control de los territorios dejados por la agrupación guerrillera. (CLACSO, 2017)

Entre estas transiciones que configuran el presente de la paz en Colombia, podremos situar desde lo planteado por Oliver Richmond (2009, 2010, 2011, 2013, 2014b, 2014a) que en Colombia han estado en disputa los siguientes proyectos de paz:

Tabla 4. Proyectos de Paz

\begin{tabular}{|l|l|l|}
\hline Proyectos de Paz & Periodo & Descripción \\
\hline Paz de la victoria & $1826-1886$ & $\begin{array}{l}\text { Este proyecto de paz se } \\
\text { caracterizó por la victoria militar, } \\
\text { entendiendo que la única } \\
\text { posibilidad de paz se establece a } \\
\text { través de ausencia de violencia y } \\
\text { la derrota del enemigo, lo cual } \\
\text { derivo en las guerras civiles } \\
\text { nacionales y regionales que tuvo } \\
\text { el Siglo XIX y el fortalecimiento del }\end{array}$ \\
\hline
\end{tabular}




\begin{tabular}{|c|c|c|}
\hline & & Ejército Nacional \\
\hline $\begin{array}{l}\text { Paz Constitucional Vs } \\
\text { Paz de la Victoria }\end{array}$ & $1886-1980$ & $\begin{array}{l}\text { Durante gran parte del Siglo XX se } \\
\text { sostiene el proyecto de paz de la } \\
\text { victoria como parte de la política } \\
\text { de Estado y en lo que se } \\
\text { concentraban los procesos de } \\
\text { negociación (Desmovilización y } \\
\text { Desarme). Sin embrago con la } \\
\text { aparición de las Naciones Unidas } \\
\text { emerge en la segunda mitad un } \\
\text { marco jurídico internacional para } \\
\text { la regulación de los conflictos que } \\
\text { se basara en la garantía de } \\
\text { derechos civiles y la } \\
\text { implementación de la } \\
\text { democracia como modelo } \\
\text { jurídico, lo cual se materializo en } \\
\text { Colombia en la disputa entre } \\
\text { sectores conservadores y y } \\
\text { progresistas con la Constitución } \\
\text { de } 1886 \text { y al final del milenio con } \\
\text { la de } 1991 \text { así como las múltiples } \\
\text { exponsiones, indultos, amnistías y } \\
\text { acuerdos jurídicos desarrollados. }\end{array}$ \\
\hline $\begin{array}{l}\text { Paz de los Movimientos } \\
\text { sociales Vs Paz } \\
\text { Constitucional Vs Paz } \\
\text { de la Victoria }\end{array}$ & $1981-2010$ & $\begin{array}{l}\text { A partir de la emergencia de } \\
\text { múltiples grupos armados en } \\
\text { Colombia se materializan } \\
\text { demandas de diferentes sectores } \\
\text { sociales a lo que se suma el } \\
\text { movimiento social configurando } \\
\text { un proyecto heterogéneo de paz } \\
\text { sobre el desmonte de la yiolencia } \\
\text { estructural del país. Este proyecto } \\
\text { entra en disputa con el Proyecto } \\
\text { de Paz constitucional que se } \\
\text { había concentrado en la } \\
\text { Constitución de } 1991 \text { y en los } \\
\text { procesos de desarme y } \\
\text { desmovilización sin contribuir a la } \\
\text { solución estructural de los factores } \\
\text { prolongadores del conflicto. Así } \\
\text { mismo entre } 2002 \text { y } 2010 \text { resurge el } \\
\text { proyecto de paz de la victoria a } \\
\text { partir del plan de gobierno de } \\
\text { Uribe Vélez que denomino }\end{array}$ \\
\hline
\end{tabular}




\begin{tabular}{|c|c|c|}
\hline & & $\begin{array}{l}\text { Seguridad Democrática y que se } \\
\text { articuló con la arquitectura } \\
\text { discursiva y militar internacional } \\
\text { de Seguridad y Defensa nacional } \\
\text { liderada por los EEUU. La disputa } \\
\text { de estos proyectos de paz se } \\
\text { refleja en procesos de } \\
\text { negociación o o de } \\
\text { implementación truncados y la } \\
\text { configuración de un imaginario } \\
\text { colectivo de paz esquiva (Pizarro, } \\
\text { 2017) que justifica moralmente la } \\
\text { indiferencia y la perpetuación del } \\
\text { conflicto armado sin solución } \\
\text { política negociada. }\end{array}$ \\
\hline $\begin{array}{l}\text { Consolidación de la } \\
\text { Paz Liberal como } \\
\text { matriz generativa de } \\
\text { la paz territorial }\end{array}$ & $2010-2016$ & $\begin{array}{l}\text { La ausencia de consenso de las } \\
\text { demandas estructurales de los } \\
\text { diferentes sectores del } \\
\text { movimiento social en torno a la } \\
\text { paz, las disputas de negociación } \\
\text { entre las guerrillas existentes (ELN y } \\
\text { FARC -EP) que fragmentan la } \\
\text { izquierda radical, } \\
\text { posicionamiento en la opinión } \\
\text { pública nacional del proyecto de } \\
\text { paz de la victoria de la Seguridad } \\
\text { Democrática, la } \\
\text { institucionalización de las } \\
\text { procesos de peacebulding y } \\
\text { statebuilding de las Naciones } \\
\text { Unidas y la consolidación } \\
\text { internacional del campo de los } \\
\text { Estudios de Paz y Conflictos } \\
\text { generan la matriz configuradora } \\
\text { de la Paz liberal que encarna el } \\
\text { plan de Desarrollo del Gobierno } \\
\text { Santos y el modelo de } \\
\text { negociación con las FARC-EP. El } \\
\text { proyecto de Paz liberal consiste } \\
\text { en la liberalización de los territorios } \\
\text { a partir de la consolidación de la } \\
\text { institucionalidad y el modelo de } \\
\text { intercambio económico, es decir } \\
\text { el fortalecimiento de la } \\
\text { democracia liberal y el y los territorios. } \\
\text { capitalismo en los }\end{array}$ \\
\hline
\end{tabular}




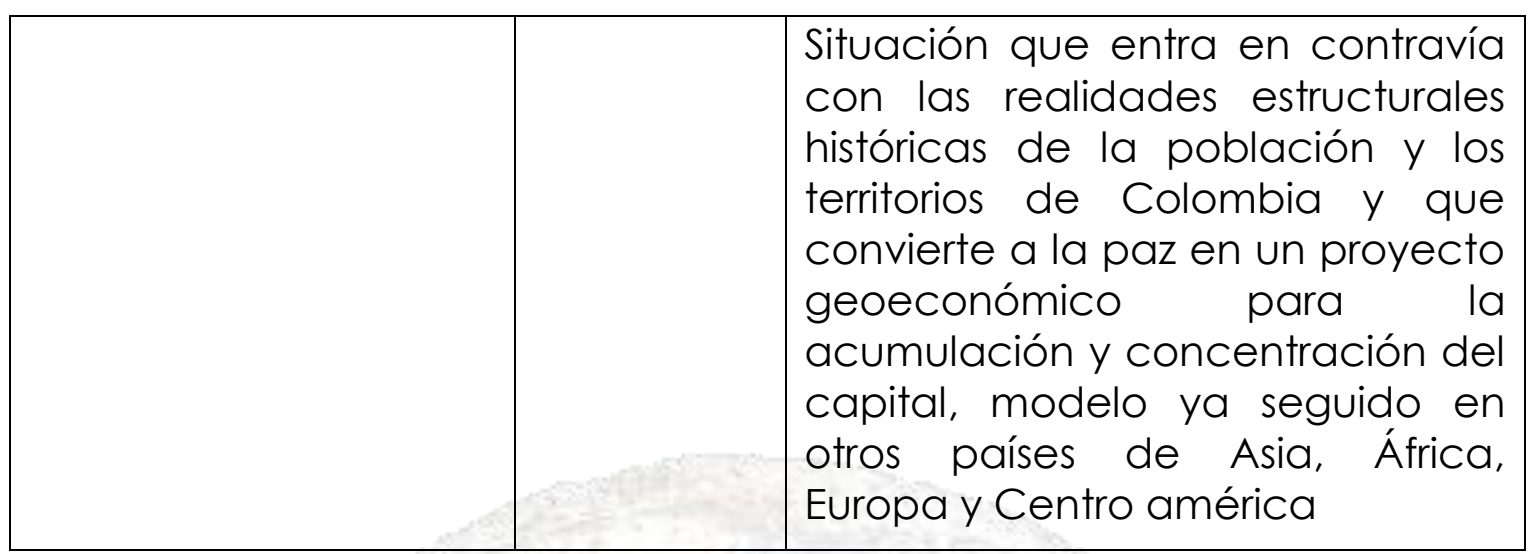

\section{Fuente: elaboración propia}

Pero estos proyectos no son deslocalizados, deshistorizados, hacen parte de una exterioridad no excluyente sino por el contrario constituyente que configuran una arquitectura discursiva global, que los glocaliza (Hartcour \& Escobar, 2007) y que hacen parte de un proyecto de paz liberal (Richmond, 2014a) vinculado al Sistema Mundo Modernidad/colonialidad (Escobar, 2003) Esto implicaría que la "verdad" sobre estos proyectos de paz está ligada circularmente a los sistemas de poder que la producen y la mantienen, y a los efectos de poder que induce y que la acompañan (Foucault, 1988). Por lo tanto, prácticas, costumbres, rituales, sistemas de relación y reproducción simbólica, transmitirán, compartirán y negociaran lo que significará para cada momento histórico, en cada contexto, lo que es, se siente y se hace como Paz.

La disputas de estos proyectos de paz en Colombia se han consolidado en una matriz generativa que es consecuencia de la instucionalización del discursos de la paz en la arquitectura internacional, convirtiendo al proyecto de paz liberal en un tiempo lineal ahistórico, homogéneo en donde se naturalizan y justifican de manera imperfecta las formas neocoloniales de opresión Sexo/género, raza/etnia y clase. El tiempo de la paz liberal es ausente de contradicciones, es el fin de la historia.

Así, si partimos de la paz como un dispositivo de saber-poder históricamente localizado, heterogéneo, desde el cual se agencian y se han agenciado de manera individual y colectiva las prácticas sociales, políticas, económicas y culturales cotidianas e históricas, donde se presentan las principales disputas, las discontinuidades y las principales regularidades que sostienen el ethos de identificación y de producción de subjetividades, que configuran el "régimen de verdad" sobre la paz en Colombia, desujetar los saberes históricos consolidados en este régimen, descolonizarlos, asumir la materia subterránea que esconde (Stuart Hall, 2010) la tentación unitaria, universalista, acumulativa (Foucault, M. 2010) se convierten en la provocación para sentir-pensarhacer. 
Este análisis decolonial-situacional sobre los proyectos de paz en Colombia requiere asumir que los entendamos como "regímenes de paz" que han estado históricamente situados, heterogéneos y en disputa y que podemos sintetizar a partir de las siguientes premisas: 1) Hablar de su pluralidad implica reconocerla como campos de lucha entre distintas posiciones históricamente localizadas que han pretendido unificar y normalizar a partir de esta categoría; 2)Los regímenes de paz son el resultado de transiciones político económicas donde su uso y apropiación se convierte en estratégicos para la artes de gobierno. 3) Estos regímenes, en momentos particulares determinan las condiciones de posibilidad que someten ciertos saberes sobre la paz en relación con alteridades demarcadas por el proceso civilizatorio colonial en relación con Raza, efnia, género, clase o condición vital 4) Estos regímenes han estado articulados hegemónicamente a la modernidad/colonialidad del sistema capitalista (Escobar, A. 2003; Castro-Gómez, S. y Restrepo, E. 2008) y a su reorganización postfordista (Castro-Gómez, S. 2007) 5) En transiciones políticas de la violencia configuran el imaginario social del por-venir a partir de infraestructuras institucionales y comunitarias para la paz (Castillejo 2012;2014; 2015;2016) 6) Están articulados imbricadamente con una arquitectura global institucional y respaldada en el discurso del capitalismo afectivo del humanitarismo (Aparicio 2017; 2012)

Así, la relación modernidad-colonialidad-capitalismo nos permite pensar los regímenes de la paz más allá de los límites temporo-espaciales del significante "paz" "mostrando cómo las formas del presente dependen de una situación histórica legada a través de prácticas coloniales que se naturalizan e imponen formas de ejercicio del poder cristalizadas con el paso del tiempo" (Castro-Gómez, S. y Restrepo, E. 2008 p. 25)la paz como efecto de las tecnologías de poder de las artes liberales de gobierno que han operado articuladamente en la historia de las sociedades moderno/coloniales, como Colombia (Sobre los deseos, las poblaciones y los territorios). Ampliar la comprensión de la paz en Colombia desde una lectura de larga duración implica entonces darle la continuidad a la rueda de la historia que esta por-venir.

\section{Referencias Bibliográficas}

Alban, A., \& Rosero, J. (2016). Colonialidad de la naturaleza: żimposición tecnológica y usurpación epistémica? Interculturalidad, desarrollo y reexistencia. 45, 27-41.

Bolívar, I., Vázquez, T., \& González, F. (2005). Violencia política en Colombia. De la nación fragmentada a la construcción del Estado. Bogotá: CINEP. 
Castillejo, A. (2015). La imaginación social del porvenir: reflexiones sobre Colombia y el prospecto de una Comisión de la Verdad (p. 54). CLACSO.

Castro-Gómez, S. (2008). Señales en el cielo, espejos en la tierra: La Exhibición del Centenario y los laberintos de la interpelación. En S. Castro-Gómez (Ed.), Genealogías de la colombianidad (p. 336). Bogotá: Pontificia Universidad Javeriana, Instituto de Estudios Sociales y Culturales Pensar.

CLACSO (2017) Terminó ta guerra, el postconflicto está en riesgo : a un año del acuerdo de paz. León Valencia Agudelo et al.] ; compilado por León Valencia Agudelo. - la ed . - Ciudad Autónoma de Buenos Aires : CLACSO ; Bogotá : Fundación Paz \& Reconciliación

Clarke, A., Friese, C., \& Washburn, R. (2015). Situational Analysis in Practice: Mapping Research with Grounded Theory. Routledge.

De la Reza, G. (2009). La Invención de la paz. De la República Cristiana del Duque de Sully a la Sociedad de Naciones de Simón Bolivar. UAMSiglo XXI.

Escobar, A. (2003). MUNDOS Y CONOCIMIENTOS DE OTRO MODO. EI programa de investigación de modernidad/colonialidad latinoamericano-, 51-86.

Estrada, J. (2015). Acumulación capitalista, dominación de clase y rebelión armada. En Contribución al entendimiento del conflicto armado en Colombia (pp. 295-360). Bogotá: Desde Abajo.

Foucault, M. (1988). Arqueología del saber. Siglo XXI.

Foucault, M. (2008). Defender la sociedad (4a ed.). Buenos Aires: Fondo de Cultura Económica de Argentina.

García-Durán, M. (1992). De la Uribe a Tlaxcala-Procesos de paz. Bogotá: CINEP.

García-Durán, M. (1995). La política de negociación con la guerrilla: Cambios de la administración Gaviria a la administración Samper, 35-61.

García-Durán, M. (2001). Veinte años buscando una salida negociada: Aproximación a la dinámica del conflicto armado y los procesos de paz en Colombia 1980-2000.

García-Durán, M. (2006a). De Turbay a Uribe: Sin Política de Paz pero con Conflicto. En En la encrucijada.Colombia en el Siglo XXI. Grupo Editorial Norma/Centro de Estudios Sociales Universidad de los Andes.

García-Durán, M. (2006b). Movimiento por la Paz 1978-2003. Bogotá: CINEP/UNDP/Colciencias.

García-Durán, M. (2009a). Colombia: conflicto armado, procesos de negociación y retos para la paz. En Tendencias de la Paz en Colombia. Retos Discursos y territorio. Bogotá: CINEP. 
García-Durán, M. (2009b). De la insurgencia a la democracia. Estudio de caso. Bogotá: CINEP/Centro Berghof/Observatorio para la paz.

Giraldo, J. (2015). Aportes sobre el origen del conflicto armado en Colombia, su persistencia y sus impactos. En Contribución al entendimiento del conflicto armado en Colombia (pp. 423-470). Bogotá: Desde Abajo.

González, B. (1996a). Economías fundacionales. Diseño del cuerpo ciudadano. En B. González (Ed.), Cultura y Tercer Mundo. Nuevas identidades y ciudadanías (pp. 17-47). Caracas: Nueva Sociedad.

González, B. (1996b). El cuerpo salvaje de la nación: Ciudadanías desplazadas (Siglo XIX), 5, 3-18.

González, F. (2015). Poder y violencia en Colombia. CINEP.

Guerrero, V. (2016). Guerras civiles colombianas. Negociación, regulación y memoria. Pontificia Universidad Javeriana.

Hartcour, W., \& Escobar (Eds.). (2007). Mujeres Y Política De Lugar. Programa Universitario de Estudios de Género, UNAM.

Instituto Kroc de Estudios Internacionales de Paz (2017) Informe sobre el estado efectivo de implementación del acuerdo de paz en Colombia.

Jaime-Salas, J. (2012). Juan Pistola: La Historia de un hombre en tiempos de la Violencia en el Sur de Colombia (Tesis de Maestría). Surcolombiana, Neiva.

Kalmanovitz, S. (Ed.). (2016). Nueva historia económica de Colombia. Bogotá: Aguilar, Altea, Taurus, Alfaguara S.A.

Machado-Aráoz, H. (2010). La "Naturaleza" como objeto colonial. Una mirada desde la condición eco-bio-política del colonialismo contemporáneo, 35-47.

Machado-Aráoz, H. (2012). Los dolores de nuestra América y la condición neocolonial. extractivismo y biopolítica de la expropiación.

Machado-Aráoz, H. (2013). Orden Neocolonial, extractivismo y ecología política de las emociones, 11-43.

Maldonado-Torres, N. (2007). Sobre la colonialidad del ser: contribuciones al desarrollo de un concepto. En El giro decolonial. Reflexiones para una diversidad epistémica más allá del capitalismo global (pp. 127-167). Bogotá: lesco-Pensar-Siglo del Hombre Editores.

Melgarejo, maría del P. (2008). Trazando las huellas del lenguaje político de La Regeneración: la nación colombiana y el problema de su heterogeneidad excepcional. En S. Castro-Gómez (Ed.), Genealogías de la colombianidad (p. 336). Pontificia Universidad Javeriana, Instituto de Estudios Sociales y Culturales Pensar. 
Moncayo, V. (2015). Hacia la verdad del conflicto: insurgencia guerrillera y orden social vigente. En Contribución al entendimiento del conflicto armado en Colombia (pp. 107-196). Bogotá: Desde Abajo.

MOVICE. (2013). Paz Sin Crímenes de Estado.Memoria y propuesta de las víctimas.

Nuñez, V. (2013). Langue, nation et identité : la construction de la nation en Colombie au XIXe siècle (Tesis Doctoral). Université Paul-Valéry Montpellier 3, Montpellier.

Oquist, P. (1978). Violencia, Conflicto y Politica en Colombia. Bogotá: Instituto de Estudios Colombianos Biblioteca Banco Popular.

Palacios, M. (2012). Violencia pública en Colombia, 1958-2010. Bogotá: Fondo de Cultura Económica.

Pécaut, D. (2001). Orden y violencia: evolución socio-política de Colombia entre 1930 y 1953. Norma.

Pizarro, E. (2017) Cambiar el futuro: historia de los procesos de paz en Colombia (1981-2016) Bogotá: Debate.

Quijano, A. (2014). Cuestiones y horizontes: de la dependencia históricoestructural a la colonialidad/descolonialidad del poder / Aníbal Quijano. CLACSO.

Ramírez-Orozco, M. (2012). La paz sin engaños. Estrategias de solución para el conflicto colombiano. México: UNAM, Centro de Investigaciones sobre América Latina y el Caribe.

Richmond, O. (2009). Liberal Peace Transitions: Between Statebuilding and Peacebuilding. Edinburgh University Press.

Richmond, O. (2010). Resistance and the post-liberal peace, 38(3), 665692.

Richmond, O. (2011). A Post Liberal Peace. Manchester UK: Routledge.

Richmond, O. (2013). The local turn in peace building: A critical agenda for peace, $34(5), 763-783$.

Richmond, O. (2014a). Peace. A very short introduction. Great Britain: Oxford University Press.

Richmond, O. (2014b). Where now for the critique of the Liberal Peace.

Rojas, C. (2001). Civilización y violencia. La búsqueda de la identidad en la Colombia del siglo XIX. Pontificia Universidad Javeriana.

Sánchez, G. (1991). Guerra y política en la sociedad colombiana. Bogotá: El Áncora.

Sánchez, G., \& Meerteens, D. (2006). Bandoleros, gamonales y campesinos: el caso de la violencia en Colombia. Penguin Random House. 
Sarmiento, F., \& Caraballo, V. (2009). Movilización social por la paz (MSP) en Colombia. Procesos de oficialización y radicalización del discurso de lapaz y los derechos humanos. En Tendencias de la Paz en Colombia. Retos Discursos y territorios. Bogotá: CINEP.

Uribe, M. T. (2003). LAS GUERRAS CIVILES Y LA NEGOCIACIÓN POLÍTICA: COLOMBIA, PRIMERA MITAD DEL SIGLO XIX, (16), 29-41.

Uribe, M. T. (2006). LAS PALABRAS DE LA GUERRA. METÁFORAS, NARRACIONES Y LENGUAJES POLITICOS: UN ESTUDIO SOBRE LAS MEMORIAS DE L ( l a ed.). La Carreta Editores.

Uribe, M. T. (201 1). La filigrana de la paz. Acuerdos, exponsiones, indultos y amnistías. En María Teresa Uribe de Hincapié Un retrato fragmentado. Ensayos sobre la vida social, económica y política de Colombia - siglos xix y xx (p. 296). Medellín: La Carreta Editores.

Uribe, M. T., \& López, L. (2008). La guerra por las soberanías. Memorias y relatos en la guerra civil de 1859-1862 en Colombia. Medellín: Instituto de Estúdios Políticos - La carreta.

Vega-Cantor, R. (2015). La dimensión internacional del conflicto social y armado en Colombia. En Contribución al entendimiento del conflicto armado en Colombia (pp. 729-812). Bogotá: Desde Abajo.

Villarraga, A. (2015). Los procesos de paz en Colombia, 1982-2014: documento resumen. Fundación Cultura Democrática. 